\title{
COVID-19 in Ophthalmology. Current Disease Status and Challenges during Clinical Practice
}

Georgios BONTZOS a, b , Anastasia GKIALA ${ }^{a}$, Christina KARAKOSTA Neofytos MALIOTISc, Efstathios T. DETORAKIS

aDepartment of Ophthalmology, 'Korgialenio-Benakio' General Hospital, 11526 Athens, Greece

bepartment of Ophthalmology, University Hospital of Heraklion, 71110 Heraklion, Greece

'Department of Ophthalmology, General Hospital of Nikaia "Agios Panteleimon", 18454 Athens, Greece

\begin{abstract}
Purpose: The novel coronavirus disease 2019 (COVID-19) has raised a global public health concern. The purpose of this review is to summarize the evidence currently available on COVID-19 for its ocular implications and manifestations from both pathogenetic and clinical standpoints.

Methods: For this narrative review, more than 100 relevant scientific articles were considered from various databases (PubMed, Google Scholar, and Science Direct) using keywords such as coronavirus outbreak, COVID-19, ophthalmology, ocular symptoms.

Results: Daily healthcare both from patient and physician perspective, as well as on some guidelines regarding prevention and management have dramatically changed over the last few months. Although COVID-19 infection mainly affects the respiratory system as well as the gastrointestinal, cardiovascular, and urinary systems, it may cause a wide spectrum of ocular manifestations. Various challenges have to be faced to minimize exposure for both patients and physicians.

Conclusion: The risk of COVID-19 infection should be considered and medical care should be prioritized for urgent cases. Appropriate management for patients with chronic cases that may result in adverse outcomes should not be neglected, while patients that can be monitored remotely should be identified.
\end{abstract}

Keywords: COVID-19, clinic management, SARS-CoV-2, coronavirus, ophthalmology.

\footnotetext{
Address for correspondence:

Neofytos Maliotis, $M D$

Department of Ophthalmology, General Hospital of Nikaia "Agios Panteleimon", Dim. Mantoivalou 3,18454 Athens, Greece

Tel. +306948672595, email: nemaliotis@gmail.com
} 
Abbreviations:

$\mathrm{CoV}=$ coronavirus;

$\mathrm{WHO}=$ World Health Organization;

MERS=Middle East respiratory syndrome;

ACE2 = angiotensin converting enzyme 2;

ARDS=acute respiratory distress syndrome;

$\mathrm{AMD}=$ age-related macular degeneration;

$\mathrm{PPE}=$ personal protective equipment

\section{INTRODUCTION}

T

he novel coronavirus, SARS-CoV-2 (COVID-19) outbreak is rapidly emerging as a global threat. With no proven treatment to date, control of the infection is of paramount importance. The ocular surface may represent a portal of entry, whereas the infectious agent may also be present in the lacrimal secretions. Ocular symptoms commonly appear in patients with severe COVID-19, and it is possible to isolate the virus from the conjunctival sac of these patients. Moreover, contact with infected eyes could be one route of disease transmission.

The purpose of this review is to summarize the currently available evidence on COVID-19 for its ocular implications and manifestations from both pathogenetic and clinical standpoints. Challenges during daily healthcare are discussed from both the patient and physician perspective and some guidelines regarding prevention and management are reviewed.

\section{ETIOLOGY AND PATHOGENESIS OF COVID-19}

\section{R rief history \\ Coronaviruses}

Coronaviruses (CoVs) belong to Coronaviridae family of the Nidovirales order and are enveloped viruses with positive sense, non-segmented, single-stranded RNA, the largest RNA genome known so far $(1,2)$. They mainly infect animals, targeting their respiratory, cardiovascular, gastrointestinal and nervous system and causing serious diseases (3). The coronavirus subfamily has four genera (alpha, beta, gamma, and delta coronaviruses), but only alpha and beta coronaviruses infect humans (4). The most common coronaviruses among humans are HCoV2-229E, -HKU1, -NL63 and -OC43 (5). Human infection by CoVs is mainly associated with respiratory and gastrointestinal manifestations $(6,7)$ and exacerbations of chronic conditions such as asthma, cystic fibrosis and chronic obstructive pulmonary disease (8), but it can also be linked to multiple organ failure and death $(9,10)$. More specifically, HCoV-NL63 has been associated with croup (laryngotracheitis) (11), while HCoV-OC43 with severe lower respiratory tract infection in children (12). No specific therapy of vaccine is available, so treatment of coronavirus-infected patients remains supportive (13-15).

Morphologically, CoVs have a spherical or pleomorphic shape with "club-like" projections, called glycosylated trimeric spike (S) proteins (16), which determine the diversity of coronaviruses and host tropism and are composed of two subunits S1 and S2. Other proteins play specific roles as well. The membrane $(\mathrm{M})$ protein contributes to the characteristic shape of the virus, the envelope (E) protein enables assembly of the virion, while the internal nucleocapsid $(\mathrm{N})$ protein forms the nucleocapsid of the virus $(17,18)$. One of the main characteristics of CoVs is their ability to mutate and form recombined, novel strains which are highly infectious to humans (19).

\section{Coronavirus outbreaks}

Three major coronavirus outbreaks have occurred in recent years. In 2002, a novel CoV strain emerged in China and spread internationally, most notably to Toronto, Canada. The World Health Organisation (WHO) reported that more than 8,000 people were infected and the fatality risk was approximately $10 \%(20,21)$. This strain caused severe acute respiratory syndrome and is known as SARS-CoV (22).

Ten years later, in 2012, another strain, called the Middle East respiratory syndrome coronavirus (MERS-CoV), was identified in Saudi Arabia. It was transmitted to humans from camels, infecting 2,468 patients and killing 34.5\% of those cases (23). Travel-related MERS cases also occurred in South Korea and the United States, and it resulted in a significant hospital-based outbreak in 2015 (21).

In December 2019, a pneumonia outbreak was reported in Wuhan, China, by the novel SARS-CoV-2. SARS-CoV-2, formerly known as 2019-nCoV, is a new CoV strain, belonging to the same category as SARS-CoV (24), and like 
SARS-CoV and MERS-CoV viruses, it is classified as beta coronavirus (25) and uses the horseshoe bats as a natural reservoir (26).

The emerging outbreak of SARS-CoV-2 disease (COVID-19) was declared a pandemic by the WHO on March 11, 2020. At the time of writing this review, there are more than $212,770,406$ patients infected worldwide and more than 4,445,854 deaths (as of 24 August 2021). To date, infected patients are the main source of infection and infectivity is directly related to the severity of the disease. In addition, asymptomatic patients or patients who incubate the virus are also infectious (27). Moreover, for the first time in the history of infectious diseases, a positive PT-PCR test has been found in recovered patients, a fact that poses serious questions about prevention of disease spread and management of those patients $(26,28)$.

The estimated fatality rate of COVID-18 is at 4-7\% (29), which is significantly lower compared to MERS (34\%) or SARS (11\%). However, total deaths from COVID-19 have far exceeded those from MERS and SARS combined (30). Infection control by applying protective measures is essential both for patient and healthcare workers (31). In fact, experience from SARS showed that healthcare workers were especially vulnerable to an uncontrolled outbreak which can shut down health services within a few days $(32,33)$.

\section{SARS-CoV-2 life cycle}

The life cycle of SARS-CoV-2 consists of a sequence of steps. Invasion of the virus into the host cell is mainly facilitated by the spike (S) membrane protein. This protein binds to specific membrane receptors, such as the angiotensin converting enzyme 2 (ACE2) $(34,35)$. The severity with which SARS-CoV-2 affects an organ is related to the amount of ACE2 in that particular organ. For instance, type II alveolar cells of the lungs, glandular cells in the Gl track and myocardial cells have a high density of ACE2 and thus, the respiratory, gastrointestinal and myocardial injury caused by SARS-CoV-2 can be explained (36-38). Following the binding of the virus on the cell membrane, the $\mathrm{S}$ protein undergoes protease cleavage. A unique characteristic of the SARS-CoV-2 virus is the existence of furin cleavage site at the $\mathrm{S} 1 / \mathrm{S} 2$ site $(35,39)$. After binding, the virus invades the host cell via endocytosis or membrane fusion. The viral RNA enters the nu- cleus and replicates, while viral mRNA is used in the biosynthesis of viral proteins. The newly assembled virions mature and are then released (25).

\section{Host response to SARS-CoV-2}

The host response to a SARS-CoV-2 infection is mainly based on T cell immunity. More specifically, the antigen is presented to T cells by dendritic cells and macrophages, which circulate in draining lymph nodes. Both CD4+ and CD8+ contribute to the host response. The former activated B cell to produce virus-specific immunoglobins and the latter destroy cells infected by the virus (25). Humoral immunity produces neutralizing antibodies that protect the host by limiting the infection in the course of the disease and preventing re-infection (40). SARS-CoV-2 induces IgG production against $\mathrm{N}$ protein, detectable after four days after disease onset. Seroconversion occurs by day 14 (41). The immunological profile of severely ill patients has revealed interesting findings, such as lymphopenia (42), concerning especially $\mathrm{T}$ cells, and increased proinflammatory cytokines such as interleukin-6 (IL-6), interleukin-10 (IL-10), granulocyte colony stimulating factor (G-CSF) and tumor necrosis factor (TNF)- $\alpha$ (43). Another finding is the ultimate exhaustion of T-cell, contributing to the progression of the disease (43). A large number of inflammatory cells has been detected in the lung infiltrate of severely ill patients with SARS-CoV-2. This infiltrate mainly consists of adaptive immune cells and innate immune cells, such as neutrophils (44). Neutrophils act protectively but also harm the lung parenchyma, through this process. Lung injury can also be promoted by cytotoxic CD8+ cells, which are present in the lung infiltrate (45). Apart from respiratory manifestations, thrombosis and pulmonary embolism are presentations of severe SARS-CoV-19 infection (46). This can be explained by the endothelial injury caused by the virus, as endothelial cells also express ACE2 (47). Endothelial injury induces high vascular permeability and facilitates viral invasion. Also, given the fact that one third of the lung cells is comprised of endothelial cells, endothelial damage contributes to the impressive lung manifestations as well (48).

The genome of SARS-CoV-2 possesses 14 open reading frames (ORF) and encodes 27 proteins (49). Like in all CoVs, the genome of 
SARS-CoV-2 includes a unique N-terminal fragment within the $S$ protein and genes for the major proteins $\mathrm{S}, \mathrm{E}, \mathrm{M}, \mathrm{N}$ occur in this order, in a 5'-3' manner (50). Whole exome analysis supports the stronger phylogenetic resemblance of SARS-CoV-2 to SARS-like bat CoV than to SARS-CoV and MERS-CoV (51). This high genome similarity suggests the Hipposideros bats in China as the common natural host of the two viruses (51). Initial genomic analysis of the SARS-CoV-2 demonstrated no significant variations, with more than $99.98 \%$ sequence identity (52). However, a recent study analyzed 103 viral genomes and proved that the virus had evolved into two types, $L$ and $S$. The $L$ type appears to be more aggressive, given its strong selective pressure, while the S type is associated with a milder disease (53).

\section{Pathophysiology. General symptoms}

COVID-19 contains a special surface glycoprotein called a "spike". The virus uses that protein to connect to ACE2 and enter the host cell. The grade of SARS-CoV-2 disease in an organ is related to the density of ACE2 enzyme in that particular organ (54).

General symptoms of patients with SARS-CoV-2 are fever, cough, headache, myalgias and fatigue (55). The enzyme ACE2 is abundant in type II alveolar cells of the lungs. This explains the fact that respiratory system is primarily affected by the virus, and may cause respiratory failure $(56,57)$. Clinical presentation of the SARS-CoV-2 varies from asymptomatic infection to acute respiratory distress syndrome (ARDS), multiple organ failure and death $(58,59)$. Lower respiratory track disease, such pneumonia as well as involvement of the upper airways (sneezing, rhinorrhea, odynophagia) are common symptoms (60).

Some patients will develop severe dyspnoea, usually after the first week of symptoms onset, require oxygen supply and even support in the intensive care unit (61). Complications of the infection include ARDS, shock and acute lung injury. Mortality rates increase in the elderly and in patients with comorbidities (61).

The density of ACE2 is also high in the glandular cells of gastric, duodenal and rectal epithelium as well as endothelial cells and enterocytes of the small intestine. As a result, COVID may appear with gastrointestinal symptoms, such as diarrhea (36).
ACE2 receptors are present in the heart as well and SARS-CoV-2 may cause acute myocardial injury and chronic damage to the cardiovascular system. In fact, acute cardiac injury was observed in $12 \%$ of infected cases admitted to the hospital in Wuhan and this percentage was higher in severe disease (38).

COVID-19 infection may cause hypercoagulaion leading to thrombosis (31\%) and venous thromboembolism $(25 \%)(62,63)$. Kidney failure is another complication related to COVID-19 infection, including patients with no previous medical history (64). Coronavirus infection could also present with a wide spectrum of ocular manifestations from anterior segment pathologies, such as conjunctivitis and anterior uveitis to sight-threatening conditions such as retinitis and optic neuritis (65-67). Moreover, affected patients may present sensory disturbances typically anosmia/hyposmia or even hearing loss $(68,69)$. Those disturbances could be attributed to ACE2 levels or genetic predisposition due to common embryonic origin of head and neck tissues (70).

\section{Transmission}

SARS-CoV-2 has a basic reproduction number (R0) of $2-2.5$, meaning that $2-3$ individuals will be infected from an index patient (71). The main route of transmission are respiratory droplets, generated during coughing and sneezing (72), and direct contact. Infected droplets can spread 1-2 $\mathrm{m}$ and contaminate nearby surfaces, where the virus can survive for days, depending on the atmospheric conditions (73).

Although respiratory tract through aerosols from an infected person is an obvious transmission route for this viral infection of COVID-19, it is probably not the only one. Droplets can invade and infect the body either through inhalation or by direct or indirect contact with the nose, mouth and eyes (58). Viral load in the nasal cavity is greater compared to the one of the throat (74). Transplacental transmission has not been described, in contrast to postnatal transmission, which is commonly observed (75). SARS-CoV-2 has been detected in urine and stool samples, suggesting possible fecal-oral transmission (76). Tap water and toilet flushes may also generate aerosols that contain the virus and spread it.

Aerosol transmission is also possible either through direct entry to the body or by contami- 
nation of surfaces (77). Droplets containing the virus as well as infected hands may contaminate the conjunctiva and thus, constitute an alternative route of infection (64-67).

There is evidence that the virus may be present in tears of patients with ocular involvement. Ocular transmission, either through direct contact with the ocular mucosa and tears or indirectly, although rare, is possible, especially in patients with ocular manifestations $(78,79)$.

In a case report, SARS-CoV-2 was isolated from ocular secretions of a patient with COVID-19 in Italy with prolonged viral RNA detection (80). However, a prospective study showed that ocular transmission of COVID-19 was quite low. In this study, researchers collected 64 tear samples from 17 COVID-19 patients between Day 3 to Day 20 from initial symptoms. Neither viral culture nor reverse transcription polymerase chain reaction (RT-PCR) detected the virus, suggesting a low risk of ocular transmission (81).

\section{Ocular manifestations}

Ocular involvement has only been described in SARS-CoV-2 infection, but not in SARS-CoV or MERS-CoV $(82,83)$. Coronavirus infection could present as well with a wide spectrum of ocular manifestations from anterior segment pathologies such as conjunctivitis and anterior uveitis to sight-threatening conditions, such as retinitis and optic neuritis (65-67). Case reports showed that conjunctivitis could be a manifestation of COVID-19. In particular, a case report described a female patient with rhinorrhoea, cough, nasal congestion and unilateral keratoconjunctivitis as the initial presentation of COVID-19. This patient did not present with fever as an initial sign, but the antipyretic medication that she had previously taken may have masked any mild fever (84).

In addition to this, a study showed that 12 out of 38 patients (31.6\%) had ocular manifestations consistent with conjunctivitis, including conjunctival hyperemia, chemosis, epiphora, and increased secretions. In the same study, one patient experienced epiphora as the first symptom of COVID-19 (81).

Other studies did not report any increased incidence of conjunctivitis in severe COVID-19 (85), while others showed that conjunctivitis could be the first diagnosis of a COVID-19 infection in a percentage varying from $0.8 \%$ to $2.8 \%$ in China $(86,87)$. A meta-analysis showed that the overall rate of conjunctivitis was $1.1 \%$ and particularly, it was $3 \%$ and $0.7 \%$ in severe and non-severe COVID-19 patients, respectively. The same study reported an increased incidence of conjunctivitis in patients admitted to the hospital with severe COVID-19 infection (67). Overall, ocular manifestations may be one of the first sign of COVID-19 infection, including various symptoms, while keratoconjunctivitis is reported to be the most common one.

\section{Vaccine development}

The SARS-CoV-2 pandemic forced the community to an unprecedent need for vaccine production. The vaccines of Pfizer-BioNTech, Moderna, Janssen (J\&J) and the Astra Zeneca/Oxford ChadOx are being distributed mainly in European and Western countries, while other countries are utilizing the Chinese Sinovac inactivated SAR-CoV-2 and Russian Sputnik V adenovirus vaccines. The total vaccine doses administered across the globe at the time of writing this review are more than 4.9 billion (88). Results from safety and efficacy studies look very promising from currently available vaccines (89-92). Generally, an ideal vaccine should have low cost, mass production, safety, while being easily distributed. Additionally, an ideal vaccine should induce, with a single dose, a strong and durable T-cell response accompanied with protective neutralizing antibody production. Moreover, the vaccine should not only be compatible with all the ages, from younger to older, but also be modifiable in order to improve its efficacy against the future emerging variants. Considering the difficulty of achieving a single dose vaccine with all of the above characteristics, it is prominent that further attempts of vaccine trials may be required. Currently there are 76 candidate vaccines at clinical and preclinical stages of development which are utilizing six different platforms (93).

\section{Novel therapies}

Chloroquine phosphate, ribavirin, penciclovir, nitazoxanide and nafamostat are the five different FDA-approved drugs that have been tested against SARS-CoV-2 (94). Two viral RNA polymerase inhibitors were also tested, remdesivir (GS-5734) and favipiravir. Subsequent in vitro evaluation of both remdesivir and chloroquine 
were found to be more effective than the other drugs (95). Since October 2020, remdesivir, an adenosine nucleoside analogue, is an FDA approved intravenous infusion COVID-19 treatment drug that probably inhibits viral replication, while simultaneously it features high affinity to sites that are blocking receptors responsible for the mechanism of the viral entry into the cell (96). Besides antiviral drugs, immunotherapy has revealed some success in treating SARS-CoV-2 infected patients. In some studies, patients who received a combination of intravenous infusion convalescent plasma from recovered patients and supportive antiviral agents showed an overall improvement in their clinical status (97). It should be noted that treatment guidelines are constantly changing following recent advances and emerging therapeutic options.

\section{Challenges in clinical practice (patient's perspective)}

Daily practice in ophthalmology has been impacted in multiple ways during the COVID-19 pandemic. We investigate how this has directly affected patients and if there are any associated risks for their healthcare.

\section{Surgical interventions}

Firstly, the total number of surgeries has been dramatically reduced to avoid virus transmission and many scheduled surgical interventions (such as cataract, glaucoma and strabismus surgery) were postponed. This is more common for patient with significant comorbidities. General anesthesia is avoided to reduce transmission risk during endotracheal intubation, and it is reserved for urgent cases $(98,99)$. Surgical procedures may serve as a means for cross-infection between patients and healthcare workers. Patient tend to prefer having elective surgery in day clinic rather than visiting a tertiary hospital, to minimize exposure. Patient's relatives are also advised to stay away from hospitals, and phone calls or video conferencing with family members should be used where it is feasible (100).

\section{Glaucoma department}

Regular outpatient visits were postponed or cancelled in several departments. Uncertainty in the duration of the outbreak makes rescheduling dates difficult (101). Patients who miss their appointments might be predisposed to sight-threa- tening complications (102). This is particularly important for patients with glaucoma $(103,104)$ as vision loss is irreversible (105). Decision making can be remote with data collected from patients (106). The downside on this practice is that decisions are usually taken without proper visual field testing (107), which violates the typical approach structure-function relationship (108).

\section{Patients receiving injections}

Patients receiving intravitreal anti-VEGF injections for chronic retinal diseases like age-related macular degeneration (AMD), diabetic retinopathy and retinal vein occlusions are also at risk $(109,110)$. Several organizations, including the American Academy of Ophthalmology, the French Society of Ophthalmology, the German Ophthalmological Society and the Royal College of Ophthalmologists, have produced guidance for physicians to assist in decision making and management of these patients $(109,111,112)$. Inevitably, patients should be prioritized according to their medical needs. Those with diabetic retinopathy and vein occlusions are less likely to suffer from irreversible vision loss in the short term, and postponement of their treatment or altering their treatment regimen can be considered $(113,114)$. It should also be highlighted that patients with diabetes are at higher risk for COVID-19 complications (115).

\section{Uveitis department}

Furthermore, the pandemic has severely affected the uveitis healthcare, with the risk of long-term deterioration of patients with ocular inflammation. With the present situation, careful selection of diagnostic tests should be made, and ophthalmologists are often called to rely on clinical examination and history taking rather than a standard set of imaging and laboratory tests $(116,117)$. Secondary manifestations like increased intraocular pressure, cystoid macular edema and choroidal neovascularization are to be reviewed regularly especially for unpredictable or acute cases.

Regarding treatment, it has been proposed that patients receiving immunomodulatory treatment for non-infectious uveitis may pose additional risk of COVID-19 infection and a more severe course of the disease. A special servicebased clinical study has been recently published to define the optimal approach for these patients (118). 


\section{Ocular oncology department}

Ocular oncology care is quite complex and requires a multidisciplinary approach for optimal outcomes. Patients need a careful evaluation on a case-by-case basis and an individualized treatment plan. Surgical cases for malignant ocular and adnexal tumor should proceed as appropriate during the pandemic. Unfortunately, the impact on the outcome can be detrimental if management is delayed for patients with malignancies $(119,120)$. This approach goes along with the understanding that there is a risk for transmission of COVID-19 during patient management, even by asymptomatic individuals. The necessity for urgent care should be balanced with the risk of viral spread. As a standard of care, the balance during a pandemic should favor the value of maximizing benefits to the population (121). With this rather bold statement we must understand that decision making may not be always easy considering medical ethics.

Patient survival should be the cornerstone of ocular oncology consultation. There is currently a recommendation to alter treatment protocols or to favor enucleation over globe salvage (122). During the pandemic, malignant tumors are to be prioritized over benign tumors and highergrade malignancies are to be prioritized over less aggressive tumors. This prioritization is proposed by the American College of Surgeons and other committees $(120,123,124)$.

\section{Challenges in Clinical Practice (Physician's Perspective) \\ Distancing}

COVID-19 has been found to be extremely transmissible, with every affected patient seeding more than two secondary cases $(125,126)$. Infection through direct transmission of droplets produced by breathing, talking, sneezing and coughing may occur after reaching the nasal mucosa or the conjunctiva. Safe distance is the first measure to be considered to avoid viral spread. An area of one meter (three feet) has been described as a risk zone in the literature $(127,128)$. It is evident that ophthalmologists are prone to getting infected because of the proximity to patients' nose and mouth, and the potential exposure to tears which may contain the virus (129). Individuals with suspicious symptoms for COVID-19 must be evaluated in an isolated area and referred for further work-up to rule out in- fection. Healthcare facilities should provide surgical masks, physical distancing and alcoholbased hand rub at hospital entrances and patient waiting areas (130). To prevent crowding in waiting areas, blocking alternating seats is also advised (99).

\section{Equipment}

The WHO guidelines recommend that healthcare workers with direct contact to patients with COVID-19 should bear personal protective equipment (PPE) including medical masks, gloves, gowns and eye protection with googles and face shields (131). Nevertheless, given the global shortage of equipment, close attention to supply chain is required to cope with the needs (132-134). Special care should be taken by healthcare providers when doffing PPE, as there is a high risk of self-contamination (135). Training for wearing and removing PPE along with hand cleaning is essential (136). A safety culture is encouraged to be established to minimize nosocomial transmission (137).

\section{Facemasks}

In Europe, respiratory protective devices must meet the European standard EN 149:2001, which classifies three disposable particulate respirators after three grades of protection; FFP1 refers to the least filtering of the three masks with aerosol filtration at least $90 \%$ for $0.3 \mu \mathrm{m}$ particles; FFP2 masks have a minimum of $94 \%$ particle filtration and FFP3 ones are the most filtering with a minimum filtration of $99 \%$, protecting against very fine particles such as asbestos and ceramic given (138). To attend patients not suspected to be infected by COVID-19, surgical masks for both patients and physicians are recommended. Although modest filtration efficacy is achieved, surgical masks are recommended in outpatient clinics to reduce viral load and prevent viral spread by asymptomatic COVID-19 (138-140). Ophthalmologists are advised to wear FFP2 or FFP3 for slit lamp examination of suspected or confirmed COVID-19 cases (130).

Viral load on surfaces and disinfection policies Studies have shown that COVID-19 could persist on plastic and steel surfaces for up to 72 hours $(70,141)$. The $\mathrm{WHO}$ recommends that disinfection and environmental cleaning procedures are 
performed routinely and consistently. Environmental surfaces can be adequately cleaned with water and hospital disinfectants such as sodium hypochlorite $(70,141)$. Frequently, touches surfaces such as doors, desks, switches, slit-lamp handles might be cleaned with household disinfectants including alcohols, hydrogen peroxide, benzalkonium or sodium hypochlorite chloride (141). It has been found that disinfectants with $62-71 \%$ ethanol could reduce coronavirus contamination exposure (70). Moreover, hand washing with soap and warm water for at least 20 seconds before and after examining patients plays a major role for controlling infection spread (142).

\section{Slit lamp breath shields}

Breath shields have been a standard feature for several slit lamps and act as a physical barrier between the examiner and patient, although the rationale is rather empirical than evidence based for reducing droplet transmission. Following COVID-19 outbreak, the efficacy of standard and enlarged breath shields was examined $(143,144)$. It was shown that breath shield was effective for reducing transmission of particles $>3 \mu \mathrm{m}$, which was considered an adequate approach, given the lack of aerosol generation during slit lamp examination. The benefits of bigger shields should be considered against the increased risk of fomite transmission for the examiner following routine tonometry or fundus examination (143).

\section{Protective eyewear}

To prevent conjunctival exposure, ophthalmologists can use googles with strong face adhesion or disposable face shields. However, it should be mentioned that clinical examination using a slitlamp can be difficult while looking through the oculars. Fundoscopy may be challenging with a limited field of view. It should also be highlighted that, with mandatory masking in clinics, lens fogging during fundus examination can become a major problem. Taping over the top of the mask with paper tape can prevent fogging due to patient's breath. An alternative time-saving option is to adjust the examination technique by gently pressing the mask against the patient's skin. While performing fundoscopy, this can be achieved by maneuvering of the ring finger of the examiner $(145,146)$. Regarding measures during surgical procedures, distance between the surgeon and patients can be increased with the use of a 3D head-up display system (147).

\section{Aerosol secretions}

Although respiratory droplets of $>5 \mu \mathrm{m}$ can be inhaled into the lungs, the possibility of airborne $(<5 \mu \mathrm{m})$ transmission such as aerosols remains controversial and further studies on this topic are needed to elucidate potential virus transmission mechanisms. Some surgical procedures, including bronchoscopy, intubation, cardiopulmonary resuscitation as well as orthopedic and dental interventions, are known to produce aerosols $(85,148)$. There is an open debate when ophthalmological procedures such as vitrectomy and phacoemulsification produce aerosols. Aerosols are produced when an air current moves across the surface of a film of a liquid. However, during vitrectomy, the cutter blade moves within the vitreous cavity in an effectively closed system (149) and the majority of the generated aerosols are carried to the cassette of the vitrectomy machine. Similarly, aerosol generation has not been noticed when a phacoemulsification probe is activated outside the eye (150).

Despite these facts, it should be highlighted that general anesthesia poses an additional risk for the staff, since endotracheal intubation generates aerosols (98). Only urgent interventions should be undertaken during the pandemic, while scheduled procedures might be postponed.

Finally, some instruments used in routine examination such as air-puff tonometer can also pose a risk due to generation of aerosol from the ocular surface and should be kept aside if possible (151).

\section{Teleophthalmology}

With the term of teleophthalmology we refer to the use of medical information exchanges from one site to another by the means of electronic communication to monitor and improve patients' health status. In fact, many healthcare systems have already invested in this technology prior to the COVID-19 pandemic. Some barriers for the worldwide use of this technology include limited reimbursement from the healthcare system, unfamiliarity with this technology and loss of in-person care (152-154).

Real-time telemedicine using live videocalls offers the possibility to get a detailed history from 
the patient and roughly examine the eye condition. Although the options are limited, the ophthalmology can examine the pupils, the corneal reflexes and perform an external examination of the eyelids and adnexa (155). The accuracy of clinical signs might be questionable, though and diagnosis should be considered twice.

Some other aspects of this technology that can be used in clinical practice include the storage of images and documents of patients which can then be forwarded and reviewed by the clinician at a later time. Remote monitoring allows physicians to collect data from patients and manage chronic conditions. The application of same remote-controlled devices should be considered here. For example, contact lens that continuously monitor changes in intraocular pressure (156). Several other user-friendly applications can be used to test visual acuity, metamorphopsias, color vision and pupil size (157-160). Even more complex tests have been proposed using handheld devices, including optical coherence tomography, fundus photographs and scanning laser ophthalmoscopy (161-163). Even if some procedures are difficult to replicate at home, storage and forwarding of patient scans can significantly reduce the examination time and limit exposure for treating physicians. This hybrid model can decrease the staff member required on site and conserve supplies (154).

The endpoint on this technology is that it can certainly assist clinical practice in several cases; however, it cannot completely replace in-person examination and consultation.
1) Urgent staff COVID-19 testing should be carried for all symptomatic workers instead of self-isolation for seven days.

2) Screening questionnaires can be distributed to any outpatient clinic. In fact, contacting patients before their appointments to ask for any suspicious symptoms can prove affective to reduce transmission risk on site.

3) Non-contact temperature check at clinic or hospital entrance

4) No visitors and a single relative to be allowed to accompany patients

5) Scheduling appointments appropriately to avoid overlapping and crowding

6) Temperature monitoring in outpatient clinics

7) Rostering the staff to avoid simultaneous exposure of all members to infected cases.

\section{CONCLUSIONS}

N $/$ eighting for the risk of contracting COVID-19 should be considered with respect to each patient. As a general rule, elective visits and surgeries should be postponed. Medical care should be prioritized for urgent cases, but without neglecting appropriate management for chronic cases that may result in adverse outcomes.

A triage procedure should be established to identify patients who should be urgently or emergently seen by the ophthalmologist versus those who may benefit from teleophthalmology may be safely rescheduled.

\section{Additional measures}

Some additional measures to be considered are also mentioned:

Conflicts of interest: none declared.

Financial support: none declared.

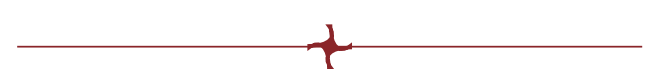

\section{R EFERENCES}

1. Zimmermann P, Curtis N. Coronavirus Infections in Children Including COVID-19: An Overview of the Epidemiology, Clinical Features, Diagnosis, Treatment and Prevention Options in Children.

Pediatr Infect Dis J 2020; 39:355-368.

2. Fung TS, Liu DX. Coronavirus infection,
ER stress, apoptosis and innate immunity. Front Microbiol 2014;5:296.

3. Amer HM. Bovine-like coronaviruses in domestic and wild ruminants. Anim Heal Res Rev 2018;19:113-124.

4. Li Q, Guan X, Wu P, et al. Early Transmission Dynamics in Wuhan,
China, of Novel Coronavirus-Infected Pneumonia.

N Engl J Med 2020;382:1199-1207.

5. Davis BM, Foxman B, Monto AS, et al. Human coronaviruses and other respiratory infections in young adults on a university campus: Prevalence, symptoms, and shedding. 
Influenza Other Respi Viruses 2018;12:582-590.

6. Cabeça TK, Granato C, Bellei N. Epidemiological and clinical features of human coronavirus infections among different subsets of patients. Influenza Other Respi Viruses 2013;7:1040-1047.

7. Esper F, Ou Z, Huang YT. Human coronaviruses are uncommon in patients with gastrointestinal illness. J Clin Virol 2010;48:131-133.

8. Zeng ZQ, Chen DH, Tan WP, et al. Epidemiology and clinical characteristics of human coronaviruses OC43, 229E, NL63, and HKU1: a study of hospitalized children with acute respiratory tract infection in Guangzhou, China. Eur J Clin Microbiol Infect Dis 2018;37:363-369.

9. Vabret A, Dina J, Gouarin S, et al. Detection of the new human coronavirus HKU1: a report of 6 cases. Clin Infect Dis 2006;42:634-639.

10. Vabret A, Mourez T, Gouarin S, et al. An outbreak of coronavirus OC43 respiratory infection in Normandy, France. Clin Infect Dis 2003;36:985-989.

11. Choi EH, Lee HJ, Kim SJ, et al. The association of newly identified respiratory viruses with lower respiratory tract infections in Korean c $\neg$ hildren, 2000-2005. Clin Infect Dis 2006;43:585-592.

12. Zhu Y, Li C, Chen $L$, et al. A novel human coronavirus OC43 genotype detected in mainland China. Emerg Microbes Infect 2018;7:173.

13. Harcourt JL, Rudoler N, Tamin A, et al. The prevalence of Middle East respiratory syndrome coronavirus (MERS-CoV) antibodies in dromedary camels in Israel. Zoonoses Public Health 2018;65:749-754.

14. Calina D, Docea AO, Petrakis D, et al. Towards effective COVID-19 vaccines: Updates, perspectives and challenges. Int J Mol Med 2020;46:3-16.

15. Nituscu GM, Paunescu H, Moschos SA, et al. Comprehensive analysis of drugs to treat SARS-CoV-2 infection: Mechanistic insights into current COVID-19 therapies. Int J Mol Med 2020;46:467-488.

16. Masters PS. The molecular biology of coronaviruses.

Adv Virus Res 2006;66:193-292.

17. Sturman LS, Holmes KV, Behnke J. Isolation of coronavirus envelope glycoproteins and interaction with the viral nucleocapsid. J Virol 1980;33:449-462.

18. Liu DX, Inglis SC. Association of the infectious bronchitis virus $3 \mathrm{c}$ protein with the virion envelope. Virology 1991;185:911-917.

19. Shi $Z, H u Z$. A review of studies on animal reservoirs of the SARS coronavirus.

Virus Res 2008;133: 74-87.
20. Li F, Li W, Farzan M, Harrison SC. Structure of SARS Coronavirus Spike Receptor-Binding Domain Complexed with Receptor. Science 2005;309:1864-1868.

21. Andersen KG, Rambaut A, Lipkin WI, et al. The proximal origin of SARSCoV-2. Nat Med 2020;26:450-452.

22. Li F, Li W, Farzan M, Harrison SC. Structure of SARS coronavirus spike receptor-binding domain complexed with receptor.

Science 2005;-309:1864-1868.

23. World Health Organization. Middle East respiratory syndrome coronavirus (MERS-CoV). 2020.

24. Docea AO, Tsatsakis A, Albulescu D, et al. A new threat from an old enemy: Re-emergence of coronavirus. Int J Mol Med 2020;45:1631-1643.

25. Yuki K, Fujiogi M, Koutsogiannaki S. COVID-19 pathophysiology: A review. Clin Immunol 2020;215:108427.

26. Tu Y-F, Chien C-S, Yarmishyn AA, et al. A Review of SARS-CoV-2 and the Ongoing Clinical Trials. Int J Mol Sci 2020;21:2657.

27. Jin $Y$, Yang $H$, Ji W, et al. Virology, Epidemiology, Pathogenesis, and Control of COVID-19. Viruses 2020;12:372.

28. Dong E, Du H, Gardner L. An interactive web-based dashboard to track COVID-19 in real time. Lancet Infect Dis 2020;20:533-534.

29. Baud D, Qi X, Nielsen-Saines K, et al. Real estimates of mortality following COVID-19 infection. Lancet Infect Dis 2020;20:773.

30. Park M, Thwaites RS, Openshaw PJM. COVID-19: lessons from SARS and MERS. Eur J Immunol 2020;50:308.

31. Gomersall CD, Joynt GM, Ho OM, et al. Transmission of SARS to healthcare workers. The experience of a Hong Kong ICU. Intensive Care Med 2006;32:564-569.

32. Booth CM, Stewart TE. Severe acute respiratory syndrome and critical care medicine: the Toronto experience. Crit Care Med 2005;33:S53-S60.

33. Chowell G, Abdirizak F, Lee S, et al. Transmission characteristics of MERS and SARS in the healthcare setting: a comparative study.

BMC Med. 2015;13:1-12.

34. Chen Y, Guo Y, Pan Y, Zhao ZJ. Structure analysis of the receptor binding of 2019-nCoV.

Biochem Biophys Res Commun 2020;525:135-140.

35. Walls AC, Park Y-J, Tortorici MA, et al. Structure, Function, and Antigenicity of the SARS-CoV-2 Spike Glycoprotein. Cell 2020;181:281-292.

36. Gu J, Han B, Wang J. COVID-19: Gastrointestinal Manifestations and Potential Fecal-Oral Transmission.
Gastroenterology 2020;158:1518-1519.

37. Li Y-C, Bai W-Z, Hashikawa T. The neuroinvasive potential of SARS-CoV2 may play a role in the respiratory failure of COVID-19 patients. J Med Virol 2020;92:552-555.

38. Zheng Y-Y, Ma Y-T, Zhang J-Y, Xie X. COVID-19 and the cardiovascular system. Nat Rev Cardiol 2020;17:259-260.

39. Belouzard S, Chu VC, Whittaker GR. Activation of the SARS coronavirus spike protein via sequential proteolytic cleavage at two distinct sites. Proc Natl Acad Sci 2009;106:5871-5876.

40. Gorse GJ, Donovan MM, Patel GB. Antibodies to coronaviruses are higher in older compared with younger adults and binding antibodies are more sensitive than neutralizing antibodies in identifying coronavirus-associated illnesses. J Med Virol 2020;92:512-517.

41. Liu W, Fontanet A, Zhang P-H, et al. Two-year prospective study of the humoral immune response of patients with severe acute respiratory syndrome. J Infect Dis 2006;193:792-795.

42. Qin C, Zhou L, Hu Z, et al. Dysregulation of Immune Response in Patients With Coronavirus 2019 (COVID-19) in Wuhan, China. Clin Infect Dis 2020;1:762-768.

43. Zhou $Y$, Fu B, Zheng $X$, et al. Pathogenic T-cells and inflammatory monocytes incite inflammatory storms in severe COVID-19 patients. Natl Sci Rev 2020;7:998-1002.

44. Xu Z, Shi L, Wang Y, Zhang J, et al. Pathological findings of COVID-19 associated with acute respiratory distress syndrome.

Lancet Respir Med 2020;8:420-422.

45. Small BA, Dressel SA, Lawrence CW, et al. $\mathrm{CD} 8(+) \mathrm{T}$ cell-mediated injury in vivo progresses in the absence of effector T cells. J Exp Med 2001;194:1835-1846.

46. Wang M, Hao H, Leeper NJ, Zhu L, Early Career Committee. Thrombotic Regulation From the Endothelial Cell Perspectives. Arterioscler Thromb Vasc Biol 2018;38:90-95.

47. Lovren F, Pan Y, Quan A, et al. Angiotensin converting enzyme- 2 confers endothelial protection and attenuates atherosclerosis. Am J Physiol Heart Circ Physiol 2008;295:1377-1384.

48. Zeng H, Pappas C, Belser JA, et al. Human pulmonary microvascular endothelial cells support productive replication of highly pathogenic avian influenza viruses: possible involvement in the pathogenesis of human $\mathrm{H} 5 \mathrm{~N} 1$ virus infection. J Virol 2012;86:667-678.

49. Song Z, Xu Y, Bao L, et al. From SARS to MERS, Thrusting Coronaviruses into the Spotlight. 
Viruses 2019;11:59.

50. Mousavizadeh L, Ghasemi S. Genotype and phenotype of COVID-19: Their roles in pathogenesis. J Microbiol Immunol Infect 2021;54:159-163.

51. Wu A, Peng Y, Huang B, et al. Genome Composition and Divergence of the Novel Coronavirus (2019-nCoV) Originating in China.

Cell Host Microbe 2020;27:325-328,

52. Zhou $P$, Yang $X-L$, Wang $X-G$, et al. A pneumonia outbreak associated with a new coronavirus of probable bat origin. Nature 2020;579:270-273.

53. Tang X, Wu C, Li X, et al. On the origin and continuing evolution of SARS-CoV-2. Natl Sci Rev 2020;7:1012-1023.

54. Hamming I, Timens W, Bulthuis $M$, et al. Tissue distribution of ACE2 protein, the functional receptor for SARS coronavirus. A first step in understanding SARS pathogenesis. J Pathol 2004;203:631.

55. Torres-Tamayo M, Calzada-León R, Rivera-Hernández AJ, et al. Diagnosis of secondary causes of precocious puberty: Clinical guideline for the diagnosis and treatment of precocious puberty. Bol Med Hosp Infant Mex 2020;77:15-18.

56. Cadegiani FA. Can spironolactone be used to prevent COVID-19-induced acute respiratory distress syndrome in patients with hypertension?

Am. J. Physiol. Endocrinol. Metab. 2020;318:587-588.

57. Li Y, Bai W, Hashikawa T. The neuroinvasive potential of SARS-CoV2 may play a role in the respiratory failure of COVID-19 patients.

J Med Virol. 2020; 92:552-555

58. Singhal T. A Review of Coronavirus Disease-2019 (COVID-19) Indian J Pediatr 2020;87:281-286.

59. Stancioiu F, Papadakis GZ, Kteniadakis S, et al. A dissection of SARS-CoV2 with clinical implications. Int J Mol Med 2020;46:489-508.

60. Huang C, Wang Y, Li X, et al. Clinical features of patients infected with 2019 novel coronavirus in Wuhan, China. Lancet 2020;395:497-506.

61. Chen N, Zhou M, Dong X, et al. Epidemiological and clinical characteristics of 99 cases of 2019 novel coronavirus pneumonia in Wuhan, China: a descriptive study. Lancet 2020;395:507.

62. Klok FA, Kruip MJHA, Meer NJM, et al. Incidence of thrombotic complications in critically ill ICU patients with COVID-19. Thromb Res 2020;191:145.

63. Cui S, Chen S, Li X, et al. Prevalence of venous thromboembolism in patients with severe novel coronavirus pneumonia. I Thromb Haemost 2020;18:1421-1424.

64. Coronavirus: Kidney Damage Caused by COVID-19 | Johns Hopkins Medicine.

65. Seah I, Agrawal R. Can the Coronavirus
Disease 2019 (COVID-19) Affect the Eyes? A Review of Coronaviruses and Ocular Implications in Humans and Animals. Ocul Immunol Inflamm 2020;28:391-395.

66. Willcox MD, Walsh K, Nichols JJ, et al. The ocular surface, coronaviruses and COVID-19.

Clin Exp Optom 2020;103:418-424.

67. Loffredo L, Pacella F, Pacella E, et al. Conjunctivitis and COVID-19: A meta-analysis.

J Med Virol 2020;92:1413-141.

68. Sriwijitalai $W$, Wiwanitkit V. Hearing loss and COVID-19: A note. Am J Otolaryngol 2020;41:102473.

69. Hannum ME, Ramirez VA, Lipson SJ Herriman RD, et al. Objective sensory testing methods reveal a higher prevalence of olfactory loss in COVID-19-positive patients compared to subjective methods: A systematic review and meta-analysis.

Chemical senses 2020;45:865-874

70. Detorakis ET, Chrysochoou F, Paliobei V, et al. Evaluation of the acoustic function in pseudoexfoliation syndrome and exfoliation glaucoma: audiometric and tympanometric findings. Eur J Ophthalmol 2008;18:71-76.

71. Dashraath $P$, Wong JLJ, Lim MXK, et al. Coronavirus disease 2019 (COVID-19) pandemic and pregnancy. Am J Obstet Gynecol 2020;222:521-531.

72. Rothe C, Schunk M, Sothmann $P$, et al. Transmission of 2019-nC oV Infection from an Asymptomatic Contact in Germany. N Engl J Med 2020;382:970-971.

73. Kampf G, Todt D, Pfaender S, et al. Persistence of coronaviruses on inanimate surfaces and their inactivation with biocidal agents. J Hosp Infect 2020;104:246-251.

74. Lu R, Zhao X, Li J, et al. Genomic characterisation and epidemiology of 2019 novel coronavirus: implications for virus origins and receptor binding. The Lancet 2020;395:565-574.

75. Karimi-Zarchi M, Neamatzadeh $\mathbf{H}$, Dastgheib SA, et al. Vertical Transmission of Coronavirus Disease 19 (COVID-19) from Infected Pregnant Mothers to Neonates: A Review. Fetal Pediatr Pathol 2020;39:246-250.

76. Zhang $X$, Tan $Y$, Ling $Y$, et al. Viral and host factors related to the clinical outcome of COVID-19. Nature 2020;583:437-440.

77. Ge Z-Y, Yang L-M, Xia J-J, et al. Possible aerosol transmission of COVID-19 and special precautions in dentistry. J Zhejiang Univ Sci B 2020;21:361-368.

78. Aalbersberg IJ, Atzeni S, Koers H, et al. Bringing Digital Science Deep Inside the Scientific Article: the Elsevier Article of the Future Project. Lib Q 2014;23:274.

79. Dockery DM, Rowe SG, Murphy MA, Krzystolik MG. The Ocular
Manifestations and Transmission of COVID-19: Recommendations for Prevention.

J Emerg Med 2020;59:137-140.

80. Colavita F, Lapa D, Carletti F, et al. SARS-CoV-2 Isolation From Ocular Secretions of a Patient With COVID-19 in Italy With Prolonged Viral RNA Detection.

Ann Intern Med 2020;173:242-243.

81. Seah IYJ, Anderson DE, Kang AEZ, et al. Assessing Viral Shedding and Infectivity of Tears in Coronavirus Disease 2019 (COVID-19) Patients. Ophthalmology 2020;127:977-979.

82. Belser JA, Rota PA, Tumpey TM. Ocular tropism of respiratory viruses. Microbiol Mol Biol Rev 2013;77:144-156.

83. Arabi YM, Balkhy HH, Hayden FG, et al. Middle East Respiratory Syndrome. N Engl J Med 2017;376:584-594.

84. Cheema M, Aghazadeh H, Nazarali S et al. Keratoconjunctivitis as the initial medical presentation of the novel coronavirus disease 2019 (COVID-19). Can J Ophthalmol 2020;55:e125-129.

85. Xia J, Tong J, Liu M, et al. Evaluation of coronavirus in tears and conjunctival secretions of patients with SARS-CoV-2 infection.

J Med Virol 2020;92:589-594.

86. Guan W-J, Ni Z-Y, Hu Y, et al. Clinical Characteristics of Coronavirus Disease 2019 in China. N Engl J Med 2020;382:1708-1720.

87. Wu P, Duan F, Luo C, et al. Characteristics of Ocular Findings of Patients With Coronavirus Disease 2019 (COVID-19) in Hubei Province, China. JAMA Ophthalmol 2020;138:575.

88. COVID-19 Dashboard by the Center for Systems Science and Engineering at Johns Hopkins University. https://coronavirus.jhu.edu/map.html.

89. Mahase E. Covid-19: Vaccine candidate may be more than $90 \%$ effective, interim results indicate. BMJ 2020;371:m4347.

90. Jones I, Roy P. Sputnik V COVID-19 vaccine candidate appears safe and effective.

The Lancet 2021;10275:642-643.

91. Knoll M.D. and Wonodi C. Oxford-AstraZeneca COVID-19 vaccine efficacy. The Lancet 2020;10269:72-74.

92. Sadoff J, Le Gars M, Shukarev G et al. Interim results of a phase $1-2$ a trial of Ad26. COV2. S Covid-19 vaccine. NEJM 2021;384:1824-1835.

93. World Health Organization. Draft of the Landscape of COVID-19 Candidate Vaccines. WHO 2020. https://www.who.int/blueprint/ priority-diseases/key-action/novelcoronavirus-landscape-ncov.pdf?ua $=1$.

94. Cascella M, Rajnik M, Aleem A, et al. Features, evaluation, and treatment of coronavirus (COVID-19). In: StatPearls [Internet]. Treasure Island (FL): StatPearls 
Publishing; 2021 Jan-. Available from: https://www.ncbi.nlm.nih.gov/books/ NBK554776/

95. Wang M, Cao R, Zhang L. et al. Remdesivir and chloroquine effectively inhibit the recently emerged novel coronavirus (2019-nCoV) in vitro. Cell Res 2020;30:269-271.

96. Eweas AF, Alhossary AA, Abdel-Moneim AS. Molecular Docking Reveals Ivermectin and Remdesivir as Potential Repurposed Drugs Against SARS-CoV-2. Front Microbiol 2021;11:592908.

97. Duan K, Bende Liu, Cesheng L et al. Effectiveness of convalescent plasma therapy in severe COVID-19 patients. Proc Natl Acad Sci 2020;117:9490-9496.

98. Tran K, Cimon K, Severn M, et al. Aerosol generating procedures and risk of transmission of acute respiratory infections to healthcare workers: a systematic review. PLoS One 2012;7:e35797.

99. Safadi K, Kruger JM, Chowers I, et al. Ophthalmology practice during the COVID-19 pandemic. BMJ Open Ophthalmol 2020;5:e000487.

100.Priego E, Wilkins P. Comics as Covid-19 response: Visualizing the experience of videoconferencing with aging relatives. Interactions 2020;27:60-61.

101.Søreide K, Hallet J, Matthews JB, et al. Immediate and long-term impact of the COVID-19 pandemic on delivery of surgical services. Br J Surg 2020;107:1250-126.

102.Davis A, Baldwin A, Hingorani M, et al. A review of 145234 ophthalmic patient episodes lost to follow-up. Eye 2017;31:422-429.

103.Jayaram H, Strouthidis NG, Gazzard G. The COVID-19 pandemic will redefine the future delivery of glaucoma care. Eye 2020;34:1203-1205.

104. Bhartiya S. Current glaucoma practice: The COVID-19 impact. J Curr Glaucoma Pract 2020;14:1-2.

105.Weinreb RN, Tee Khaw P. Primary open-angle glaucoma. Lancet 2004; 363:1711-1720.

106.Clarke J, Puertas R, Kotecha A, et al. Virtual clinics in glaucoma care: face-to-face versus remote decision-making. Br J Ophthalmol 2017;101:892-895.

107.Quaranta L, Riva I, Gerardi C, et al. Quality of life in glaucoma: a review of the literature. Adv Ther 2016;33:959-981.

108.Korobelnik J-F, Loewenstein A, Eldem B, et al. Guidance for anti-VEGF intravitreal injections during the COVID-19 pandemic.

Graefe's Arch Clin Exp Ophthalmol 2020;258:1149.

109.Lanzetta $P$, Loewenstein $A$, Committee VAS. Fundamental principles of an anti-VEGF treatment regimen: optimal application of intravitreal antivascular endothelial growth factor therapy of macular diseases. Graefe's Arch Clin Exp Ophthalmol 2017;255:1259-1273.

110.Shmueli O, Chowers I, Levy J. Current safety preferences for intravitreal injection during COVID-19 pandemic. Eye 2020;4:1-3.

111.Stone LG, Devenport A, Stratton IM, Talks JS. Macula service evaluation and assessing priorities for anti-VEGF treatment in the light of COVID-19. Graefe's Arch Clin Exp Ophthalmol 2020;25:1-7.

112.Siedlecki J, Brantl V, Schworm B, et al. COVID-19: ophthalmological aspects of the SARS-CoV 2 global pandemic. Klin Monbl Augenheilkd 2020;237:675.

113.Schmidt-Erfurth U, Lang GE, Holz FG, et al. Three-year outcomes of individualized ranibizumab treatment in patients with diabetic macular edema: the RESTORE extension study. Ophthalmology 2014;121:1045-1053.

114.Bressler NM, Beaulieu WT, Glassman AR, et al. Persistent macular thickening following intravitreous aflibercept, bevacizumab, or ranibizumab for central-involved diabetic macular edema with vision impairment: a secondary analysis of a randomized clinical trial. JAMA Ophthalmol 2018;136:257-269.

115.Fang L, Karakiulakis G, Roth M. Are patients with hypertension and diabetes mellitus at increased risk for COVID-19 infection? Lancet Respir Med 2020;8:e21.

116.Smith JR, Lai TYY. Managing Uveitis During the COVID-19 Pandemic. Ophthalmology 2020;127:e65-e67.

117.Jabs DA, Busingye J. Approach to the diagnosis of the uveitides. Am J Ophthalmol 2013;156:228-236.

118.Agrawal R, Testi I, Lee CS, et al. Evolving consensus for immunomodulatory therapy in noninfectious uveitis during the COVID-19 pandemic. Br J Ophthalmol 2020;25:316776.

119.Shinde RS, Naik MD, Shinde SR, et al. To Do or Not to Do? - A Review of Cancer Surgery Triage Guidelines in COVID-19 Pandemic. Indian J Surg Oncol 2020;11:1-7.

120.Manjandavida FP, Honavar SG, Kim U, et al. Ocular oncology practice guidelines during COVID-19 pandemic-An expert consensus. Indian J Ophthalmol 2020;68:1281.

121.Emanuel EJ, Persad G, Upshur R, et al. Fair allocation of scarce medical resources in the time of Covid-19. N Engl J Med 2020;382:2049-2055.

122.Skalet AH, Allen RC, Shields CL, et al. Considerations for the Management and Triage of Ocular Oncology Cases during the COVID-19 Pandemic. Ocul Oncol Pathol 2020:6:1-4.

123.COVID ACS. Guidelines for Triage of
Cancer Surgery Patients. ACS website 2020;AD;24.

124.Lee AWM, Xu Z-Y, Lin L, et al. Advocacy to provide good quality oncology services during the COVID-19 pandemic-Actions at 3-Levels. Radiother Oncol 2020;149:25-29.

125.Remuzzi A, Remuzzi G. COVID-19 and Italy: what next? Lancet 2020;395:1225-1228.

126.Wu JT, Leung K, Leung GM. Nowcasting and forecasting the potential domestic and international spread of the 2019-nCoV outbreak originating in Wuhan, China: a modelling study. Lancet 2020;395: 689-697.

127.Coia JE, Ritchie L, Adisesh A, et al. Guidance on the use of respiratory and facial protection equipment. J Hosp Infect 2013;85:170-182.

128.Subhash SS, Baracco G, Miller SL, et al. Estimation of needed isolation capacity for an airborne influenza pandemic. Heal Secur 2016;14:258-263.

129.Xia J, Tong J, Liu M, et al. Evaluation of coronavirus in tears and conjunctival secretions of patients with SARS-CoV-2 infection.

J Med Virol 2020;92:589-594.

130.Romano MR, Montericcio A,

Montalbano C, et al. Facing COVID-19 in Ophthalmology department. Curr Eye Res 2020;45:653-658.

131.Organization WH. Rational use of personal protective equipment for coronavirus disease (COVID-19) and considerations during severe shortages: interim guidance. WHO 2020. https://www.who.int/publications/i/item/ rational-use-of-personal-protectiveequipment-for-coronavirus-disease(covid-19)-and-considerations-duringsevere-shortages.

132.Xie J, Tong Z, Guan X, et al. Critical care crisis and some recommendations during the COVID-19 epidemic in China. Intensive Care Med 2020;46:837-840.

133. Qiu H, Tong Z, Ma P, et al. Intensive care during the coronavirus epidemic. Springer 2020;46:576-578.

134.Wong JEL, Leo YS, Tan CC. COVID-19 in Singapore-current experience: critical global issues that require attention and action. JAMA 2020;323:1243-1244.

135. Cook TM. Personal protective equipment during the coronavirus disease (COVID) 2019 pandemic-a narrative review. Anaesthesia 2020;75:920-927.

136. Bouadma L, Lescure F-X, Lucet J-C, et al. Severe SARS-CoV-2 infections: practical considerations and management strategy for intensivists. Intensive Care Med 2020;46:579-582.

137.Tan LF. Preventing the transmission of COVID-19 amongst healthcare workers. J Hosp Infect 2020;105:364-365.

138.Tang SWK, Romano MR, Wong DHT, et al. The use of personal protective 
equipment in clinical ophthalmology during corona virus disease-2019: a review of international guidelines and literature.

Curr Opin Ophthalmol 2020;31:435-446.

139.Lim LW, Yip LW, Tay HW, et al. Sustainable practice of ophthalmology during COVID-19: challenges and solutions.

Graefe's Arch Clin Exp Ophthalmol 2020; 258:1427-1436.

140.Xiao Y, Torok ME. Taking the right measures to control COVID-19. Lancet Infect Dis 2020;20:523-524.

141. Van Doremalen N, Bushmaker T, Morris DH, et al. Aerosol and surface stability of SARS-CoV-2 as compared with SARS-CoV-1.

N Engl J Med 2020;382:1564-1567.

142.Mittal R, Ni R, Seo J-H. The flow physics of COVID-19. J Fluid Mech 2020;894.

143.Poostchi A, Kuet M-L, Pegg K, et al. Efficacy of slit lamp breath shields. Eye 2020;34:1185-1186.

144.Liu J, Wang AY, Ing EB. Efficacy of slit lamp breath shields. Am J Ophthalmol 2020;218:120-127.

145.Li J-PO, Lam DSC, Chen Y, Ting DSW. Novel Coronavirus disease 2019 (COVID-19): The importance of recognising possible early ocular manifestation and using protective eyewear. Br J Ophthalmol 2020;104:297-298.

146.Mungmungpuntipantip $R$, Wiwanitkit V. Ocular manifestation, eye protection, and COVID-19. Graefe's Arch Clin Exp Ophthalmol 2020;258:1339.

147.Iovino C, Caporossi T, Peiretti E.
Vitreoretinal surgery tip and tricks in the era of COVID-19.

Graefe's Arch Clin Exp Ophthalmol 2020;16:1-2.

148.Harding H, Broom A, Broom J. Aerosol generating procedures and infective risk to healthcare workers: SARS-CoV-2-the limits of the evidence.

J Hosp Infect 2020;105:717-725.

149.Li KKW, Joussen AM, Kwan JKC, Steel DHW. FFP3, FFP2, N95, surgical masks and respirators: what should we be wearing for ophthalmic surgery in the COVID-19 pandemic? Graefe's Arch Clin Exp Ophthalmol 2020;258:1587-1589.

150.Koshy ZR, Dickie D. Aerosol generation from high speed ophthalmic instrumentation and the risk of contamination from SARS COVID19. Eye 2020;4:1-2.

151.Britt JM, Clifton BC, Barnebey HS, Mills RP. Microaerosol formation in noncontact'air-puff'tonometry. Arch Ophthalmol 1991;109:225-228.

152.Dorsey ER, Topol EJ. State of telehealth. N Engl J Med 2016;375:154-161.

153.Hollander JE, Carr BG. Virtually perfect? Telemedicine for COVID-19. N Engl J Med 2020;382:1679-1681.

154.Kalavar M, Hua H-U, Sridhar J. Teleophthalmology: an essential tool in the era of the novel coronavirus 2019. Curr Opin Ophthalmol 2020;31:366-373.

155.Saleem SM, Pasquale LR, Sidoti PA, Tsai JC. Virtual ophthalmology: telemedicine in a Covid-19 era. Am J Ophthalmol 2020;216:237-242.

156.Mansouri K, Rao HL, Weinreb RN, Group A-02 S. Short-Term and Long-Term Variability of Intraocular
Pressure Measured with an Intraocular Telemetry Sensor in Patients with

Glaucoma.

Ophthalmology 2021;128:227-233.

157.Pathipati AS, Wood EH, Lam CK, et al. Visual acuity measured with a smartphone app is more accurate than Snellen testing by emergency department providers.

Graefe's Arch Clin Exp Ophthalmol 2016;254:1175-1180.

158.Ozgur OK, Emborgo TS, Vieyra MB, et al. Validity and acceptance of color vision testing on smartphones. J Neuro-ophthalmology 2018;38:13-16.

159.Hernández-Sierra JF, Tellez-Quijada $F$, Hernández Gómez CA, et al. Estimation and interrater reliability of pupillography by digital mobile app: Digital movil pupillography app validity. Eur J Ophthalmol 2020;1120672120949752.

160.Bastawrous A, Cheeseman RC, Kumar A. iPhones for eye surgeons. Eye 2012;26:343.

161. Chew EY, Clemons TE, Bressler SB et al. Randomized trial of the ForeseeHome monitoring device for early detection of neovascular age-related macular degeneration. The HOme Monitoring of the Eye (HOME) study design-HOME Study report number 1. Contemp Clin Trials 2014;37:294-300.

162.DuBose T, Nankivil D, LaRocca F, et al. Handheld adaptive optics scanning laser ophthalmoscope. Optica 2018;5:1027-1036.

163.Li P, Paulus YM, Davila JR, et al. Usability testing of a smartphone-based retinal camera among first-time users in the primary care setting. BMJ Innov 2019;5:120. 